\title{
عروض مرجعية
}

\section{دليل شركات البترول}

عرض وتثيم

شيماء إسماعيل عباس إسماعيل ماجستير فى الآداب من قسم المكتبات والوثائق والمعلومات - جامعة القاهرة

ShimooVVI@yahoo.com
مصر. وزارة البترول والثروة المعدنية. دليل

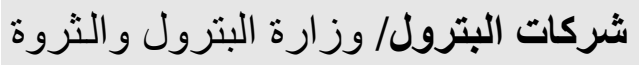

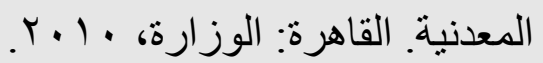
يسترجع من http://www.petroleum.gov.eg/ ar/PublicServices/Petroleum Companies/Pages/default.aspx

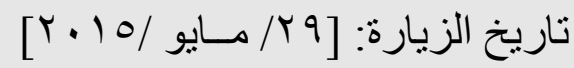

تتعــدد فئـات مــصادر المعلومــات

المرجعيـة وتتنوع، ولكنها تتضـافر معًا من أجل مساعدة كل باحث ودارس ومهتم في مجـال موضـوعي محـدد وتقديم يـــ العـون و المسـاعدة لاختصاصـيـي المر اجـع لتوفيـر خدمــة مرجعيـة فاعلـة متمـيزة تجيـب عـن تساؤلات و استفسار ات المستقيدين بسر عة توفـر علـى إعـداد "دليـل شـركات "لبترول" وزارة البترول و الثروة المعدنيـة بجمهوريـة مصر العربيـة التي أنشئت في مـارس عـام سلو (م، وهى وز ارة مستقلة
ودقة. وتُفيد أدلة الهيئات و الكيانات في التعرف على معلومـات عـن المؤسـسات و الهيئـات و المنظمــات و الجمعيــات فــي المجــالات 
للـثروة المعدنيــة (المـساحة الجيولوجيـة المسصرية سـابقًا) للـوزارة في عـ أ أكثوبـر ع . . r م أصبح تطوير و إعـادة هيكلة قطساع الثروة المعدنية هدفًا مهمًا تسعى الوزارة إلى مئح تحقيقه. ويعتبر "دليل شركات البترول" أحد الخدمات التي تساعد المواطنين في التعرف على معلومـات عن شـركات البـترول في مصر. وقـــ أتاحـت وزارة البـترول والـثروة المعدنية "دليل شركات البترول" إلكترونيًا مـن خـلال موقـع "وزارة البترول والثروة المعدنيـة" الذي يعتبر قنـاة مهمـة للاتصال و التو اصل و التفاعل مـع المجتمـع المصري تعمـل علـى إتاحـة البيانـات و المعلومــات و الأخبـار (المحليــة و العالميـة) و الأحــداث المهمة في مجال البترول والثروة المعدنيـة بالإضـافة إلى الخدمات التي تهم المواطن المصري ويجد فيها مـا يلبي احتياجاته على لـى http:/ العنـــوان الإلكترونـــي الآتــي WwW.petroleum.gov.eg/ar/ $\underline{\mathrm{P} u \text { b } 1 \text { i c }} \mathrm{S}$ e $\mathrm{r} v \mathrm{i}$ c e $\mathrm{s} /$ $\underline{\text { PetroleumCompanies/Pages/ }}$ $\underline{\text { default.aspx }}$

يقدم "دليل شركات البترول" بيانات

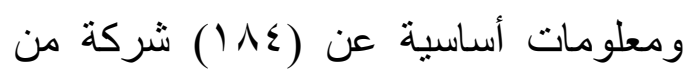

$$
\begin{aligned}
& \text { تتظم وتباشـر صـناعة البـترول في مصر } \\
& \text { وتهدف إلى : } \\
& \text { ا ـ دعـم الاحتياطيـات مـن البـترول والغـاز } \\
& \text { وزيادة إنتاجهما. } \\
& \text { Y. الوفـاء باحتياجـات الـسوق المحلـى مـن } \\
& \text { المنتجــات البتروليـــة و البتروكيماويــــة } \\
& \text { و الثرو ات المعدنية وتحقيق معدلات النمو } \\
& \text { المستهدفة للاقتصاد القومي. }
\end{aligned}
$$

r. تأمين إمدادات البترول و الغـاز الطبيعي مـن خـلال التوسـع في أنشطة البحـث و الاستكشاف وتنويـع المــادر و العملـل

$$
\text { على تعديل مزيج الطاقة. }
$$

ع. دعم الصـادر ات وزيـادة دخل مصر من

$$
\text { النقد الأجنبي وحصيلة خزانة الدولة. }
$$

○ـ وضـع الخطط القوميـة الو اضـحة القابلـة

للتنفيذ.

7. زيـادة فـرص العمـل للـشباب وتحسين

مهـار ات العـاملين وبنـاء قـوى بـشرية

وطنية ذات كفاءة عالية.

V. تحقيـق أعلى قيمـة مضافة مـن الثروات

$$
\text { الطبيعية. }
$$

^ـ الحفــاظ علـى معـايير البيأــة والتنميــة

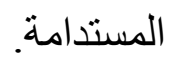

9 ـ دعم التعامل مع العـالم المتقدم واستيعاب

$$
\text { التكنولوجيا. }
$$

و عقب انضمام الهيئة المصرية العامـة 
ويمكن استرجاع البيانات و المعلومات الكاملة عن شركات البترول عبر الصفحة الرئيسية لموقع "وزارة البترول والثروة المعدنية" من خلال النقز على أيقونة خدمات المواطنين التي تنقل المستخدم لواجهة تعرض عدد من الأدلة والخدمات التي تخدم المواطن المصري، ثم النقر على التى رابط بعنوان "دليل شركات البترول" الذي ينقل المستخدم إلى الصفحة الرئيسية للاليل التي تساعده على البحث فيه، ويتم البحث في التي التيل الدليل عقب تحديد المستخدم لاستراتيجية البحث عن طريق تحديد نوع الثركة (مشترك- قطاع عام- استثماري- أجنبي) أو عن أون كتابة اسم الثركة أو عن طريق الربط بين الدخلين معًا ثم على زر (بحث).

وتظهر المعلومات عن كل شركة في شكل مختصر يوضح اسم الثركة فقط الذي يعمل رابطًا تشعيبيًا يساعد النقر عليه المستفيد في استعراض كافة المعلومات الكاملة عن شركة بعينها بشكل أكثر تفصبلاً،

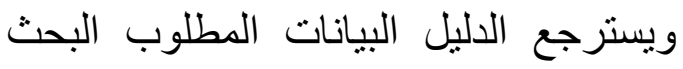
عنها بسرعة فائقة ودقة متناهية لا تتجاوز بضع ثوان، وكما يوفر الدليل إمكانية الربط

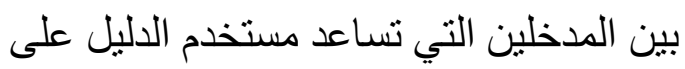
البحث فيه على النحو السابق ذكره.
شركات البترول سواء أكانت قطاعًا عامًا أم

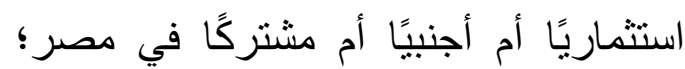

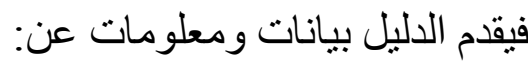
- م (ro) شركة من شركات البترول المشتركة متل شركة بتروسيلة، وشركة شمال العلمين للبترول (نالبيتكو).

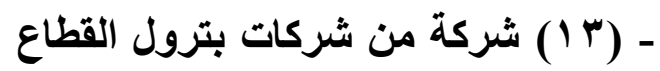
العام مثل الثركة المصرية للثروات التعدينية، وشركة النصر للبترول. - الاستثمارية مثل شركة اجيسيكو، لثنات و الوطنية لتسويق منتجات البترول. الأجنبية مثل الثركة المصرية الوطنية للاستكثاف (اللاينس)، وشركة دبلن الدولية للبترول مصر المحدودة (دبلن). تتحــصر المــداخل القابلــة للبحـــث و الاسـترجاع الـتي مـن شـأنها مسساعدة المستخدم في البحث داخل الدليل واسترجاع المعلومات و البيانات المطلوبة عن شركات البترول ما بين مدخلين هما :

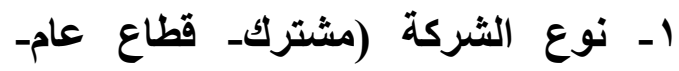

$$
\text { (ستثماري- أجنبي). }
$$

r- اسم الثركة المراد استعراض معلومات الثيات 
عدد من الروابط التشعيبية التي يساعد النقر على أي منها على تقديم معلومات مهمـة عن الوزارة (نبذة تاريخيةـ استر اتيجية الوزارةالهيكل التنظيمي- تواريخ وأحداثـ نبذة عن الوزيـر ـ... الــخ)، و أيقونــات أخـرى مثـلـ (قـو انين وقـرار ات، وخـدمات المـواطنين، و أعمـــال ومـــشرو عات، و اســـتثمار ات، و علاقـات دوليـة) ويندر ج تحـت كل أيقونـة منها عدد من الروابط التشعيبية التي يمكن للمستفيد الاختيار من بينها بما يلبي احتياجاته ويـثري معلوماتــه، بالإضــافة إلـى أيقونــة (الرئيسية) التي تمكن المستخدم من الرجوع إلى الصفحة الرئيسية لموقع "وزارة البترول والـثروة المعدنبـة"، و أيقونـات أخـرى مثنل (اتصل بنـاــــالاقتر احـاتـ خريطـة الموقـعمواقع مهمة- ... الخ)، و عدة صور تشعيبية أخرى بالثريط الجانبي للموقع تعمل كرو ابط تنقـل المستخدم إلـى واجهـات تعـرض لـه معلومـات مهمــة ومفيـدة مثنل (حقـائق عـن البـترول والـثروة المعدنيـةـ . . 1 عـام مـن إنجاز ات الوزارة- أهم المؤشرات و البيانـاتــ

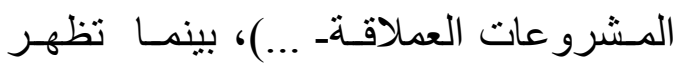
الإحــالات إلــى المواقـع الأخــرى علـى العنكبوتيـة العالميـة (الويـب : Web) التيـي تربط بين الموقع أو الدليل والمواقع الأخرى

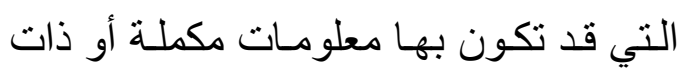

ويسهل الوصول إلى "دليل شركات البترول" من خلال محركات وأدلة البحث المختلفة، فيتاح الوصول إلى الدليل من خلال آليات البحث المتعددة مثل ياهوو (Yahoo)، وجوجل (Google)، وبينج (Bing)، ويتاح بلغتين هما: اللغة العربية، واللغة الإنجليزية وفقًا للغة الو اجهة التي يطلع من خلالها على موقع "وزارة البترول والثروة المعدنية"؛ فان كان المستخدم يطلع على الواجهة العربية لموقع "وزارة البترول والثروة المعدنية" فيمكنه استعر اض "دليل شركات البترول" والبحث فيه والإفادة منه باللغة العربية، وإن كان يطلع على الواجهة الإنجليزية لموقع "وزارة البترول والثروة المعدنية" فيمكنه تصفح "دليل شركات البترول" والبحث فيه والإفادة منه باللغة الإنجليزية.

\section{وبـصفة عامـة، يتـسم "دليـل شـركات}

البترول" بالبساطة و الوضـوح بمـا يجعله لا يحتاج لإحسالات داخليـة للربط بين مكوناتـه؛ لـذا فـلا يوفـر الـدليل إحـالات تـسـاعد في الوصـول إلـى أمـاكن أخـرى داخلـه، ولكنـه يوفـر عـدة إحـالات تـساعد المستخدم في الانتقال لو اجهات أخرى داخل موقع "وزارة البترول والثروة المعدنيـة" مثل أيقونـة (عن الوزارة) التي تسمح للمستفيد بالاختيـار بين 
المرجعية بما يساعد في جذب المستخدمين إلى استخدامها؛ فقد أدت بساطة وسهولة استخدام "دليل شركات البترول" إلى عدم حاجته إلى وجود دليل لاستخدامه؛ لذا فلا يوفر الدليل دليلًا لإرشاد المستقبد لكيفية استخدامه على الثناثات المتتابعة. ويتم تقديم الدعم و المساعدة للمستفيد عبر

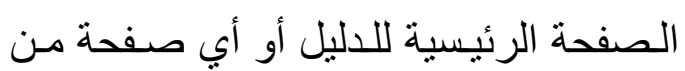
صفحاته الفرعية بالنقر على وصلة (اتصل التصل بنـا) الموجـودة بالـشريط العـــوي لموقـع "وزارة البترول و الثروة المعدنية" التي تنقل المستخدم إلي نافذة بها وسائل مختلفة لدعم مستخدم الـليل، والتي يمكن مـن خلالها الاتصال و التو اصل مع المسئولين عن إدارة

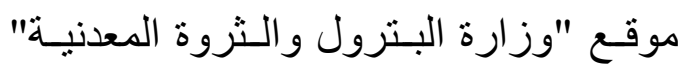
ومن ثم الدليل، وتتمثل هذه الوسائل في : 1- عنـوان الـوزارة (Address) يمكن المستخدم من إرسـال تعليقاتـه أو

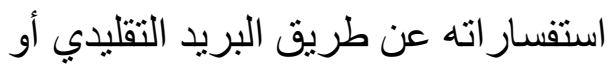
عن طريق مقابلة المباثرة بالمسئولين

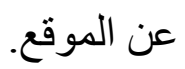
ז- التليفون (Telephone) : الذي يساعد مستخدم الدليل على إبداء آرائه عن الـن

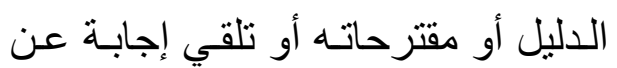
استفسار اته عن طريق الاتصال الهاتفي. r- البريـــ الإكترونــ (E-mail) : الـذي
صلة على هيئة أيقونة بعنو ان "مو اقع مهـة" بالشريط العلوي للاليل والتي يعاون النقر عليهـا في اسـتـعر اض المواقع المهــة ذات الصلة التي يقسمها الدليل إلى ثلاث فئات : ـ مواقع الوزارات والهيئات المصرية. ـ مواقع شركات البترول العالمية. ـ مواقع شركات قطاع البترول.

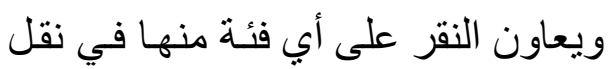
المستخدم إلى واجهة تعرض له قائمة بأسماء المو اقع الإلكترونيـة التي تندرج تحت هذه الفئة والتي يساعد النقر على اسم أي موقع منها في إحالة المستخدم للموقع مباشرة. وكما هو الحال في الغالبية العظمى من المصادر المرجعية الإلكترونية لا يوفر"دليل شركات البترول" نشرة إخبارية أو موجز

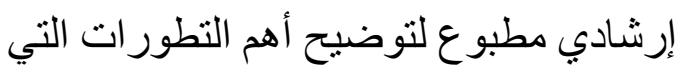
تطر أ على الدليل وآخر التحديثات و على مَنْ

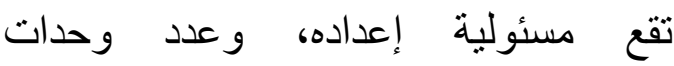
المعلومات التي يقدم الدليل معلومات عنها، ونطاق التغطية الكمية والككانية والموضوعية، والأشكال التي يظهر فيها الدليل، وتاريخ إنثاء الدليل وتاريخ إناحته إلكترونيًا... الخ، أو مقدمة تسرد هذه التهاه

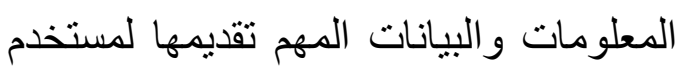
الدليل، ولما كانت سهولة الاستخدام أحد العوامل المهمة لنجاح مصادر المعلومات 
يعمل أي اسم منها رابطًا تشعيبيًا يساعد النقر عليه في استعر اض المعلومات الكاملة عن شركة بعينها بشكل مفصل، وتتفاوت المعلومات التي يقدمها الدليل طولًا من وحدة

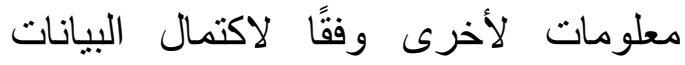
اليُجمعة عن كل شركة من شركات البترول ولكنه غالبًا ما يقدم عن كل شركة بيانات تتر اوح ما بين :

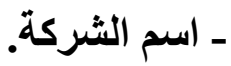

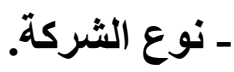
ـ العنــــــوان. ـ شعار الشركة. - مقارم صندوق البريد. - أرقام التليفون.

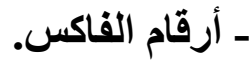
- رقم التلكـس. ـ ـ رقم/ أرقام الخط الساخن. - 2 - التليغراف. - الموقع الإكتروني. ومن جهةٍ أخرى، لا يوفر الدليل أيقونة

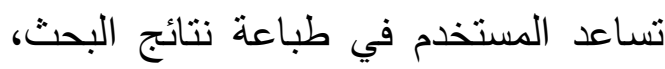
ويمكن للمستخدم القيام ببحث جديد من خلال الدليل بالنقر على زر بعنوان (إلغاء

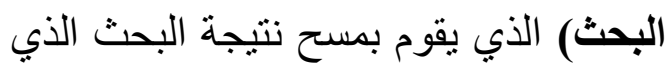

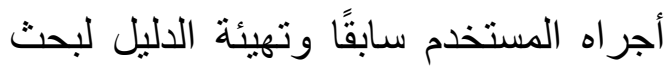
جديد عقب إعادة تحميل الصفحة الرئيسية
يعـاون مستخدم الدليل على إرسـال أي اقتر احـات أو ملاحظـات أو استفسار ات إت بشأن الدليل إلى القـائمين على إعداده و إتاحته وتلقي ما يجيب عنها. يقدم "دليل شركات البترول" بيانـات

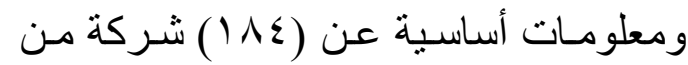

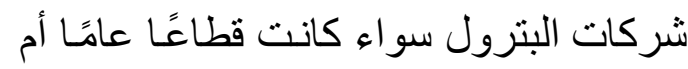

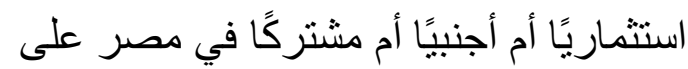

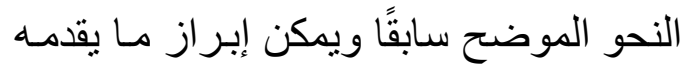
الدليل من معلومـات على نحو مفصل كما يأتي : n عبر الصفحة الرئيسية لموقع "وزارة البترول والثروة المعدنية" بالنقر على أيقونة خدمات المو اطنين الموجودة بالثريط العلوي من الموقع، ثم النقر على رابط بعنوان "دليل شركات البترول" الذي ينقل المستخدم إلى الى

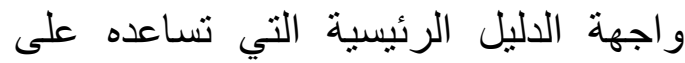
البحث فيه، ويتم البحث في الدليل بعد تحديد المستخدم للاستراتيجية البحث باستخدام

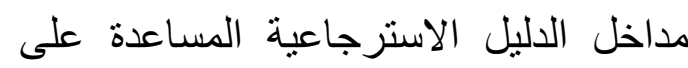
البحث فيه باختيار نوع الثركة (مشتركقطاع عام- استثماري- أجنبي) أو كتابة اسم

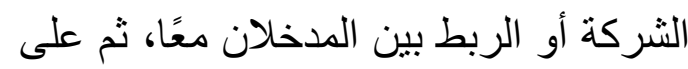
زر(بحث).

وتظهر نتيجة البحث في شكل مختصر يتمثل في اسم الثركة / الثركات فقط و الذي تُشي 
الدليل على الخط المباشر أو أجزاء منها وفقًا

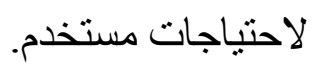

وعلى جانـب آخر، جـاء تصميم الدليل

بسيط بـإخر اج فـني غـير متكلـف يحقـق الغرض المطلوب منه باستخدام قدر مناسـب من عناصـر التصميم (الرموز ـ الأيقونـاتــ القـو ائم- ...) بـألو ان متناسـقة متباينـة على لـى الشاشة وباستخدام خطوط الطباعة المختلفة ـ الأحمـر لاسـم الـشركةـ الأسـود للبيانـات و المعلومات الأساس التي يقدمها الدليل عن الن كل شـركةـ الـتي ظهـرت بأحجــام مناسـبة

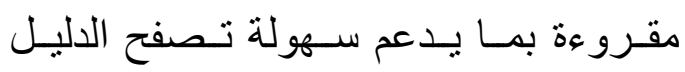

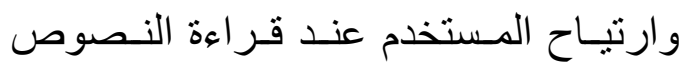
و المعلومات التي يقدمها، وقد تميزت أيضًا الطباعة بالوضوح و النقاء و الجودة. وقد أتاحت "وزارة البترول والثروة المعدنيـةة" "دليـلـ شــركات البـترول" إلكترونيًا مجانـا مـن خـلال موقـع "وزارة

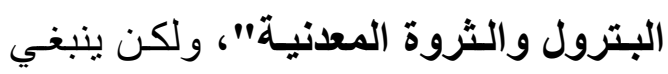
مر اعــاة التكـــاليف الأخــرى الخاصــــة بـالأجهزة، وبـر امج التشغيل، والطباعـة، والـصيانة، ورسـوم الاتـــال بالإنترنــ، وبر امج التصفح و البحـث في الإنترنـت... و غير ها من تكاليف معتادة مطلوبة للاتصال بالإنترنت. وعلى النحو السابق عرضه، تتضح

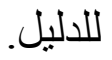
ولم يصمم "دليل شركات البترول" للعمل باستخدام سرعة اتصال أو واجهة تعامل محددة ؛ إذ إنه يمكن تشغيله باستخدام أنواع متعددة من الحاسبات وباستخدام أكثر من نوع من برامج التشغيل ودون فرض نوع محدد من الاتصالات على المستخدمين، وبصفة عامة جاءت المتطلبات المادية و البرمجية والتجهيزات اللازمة لتشغيل وتصفح الدليل معتدلة؛ و التي تتمثل في العمل على أجهزة حاسوب شخصية أو محمولة تعمل باستخدام إصدار ات نظام تشغيل النو افذ Windows ^, v, XP, ) المختلفة مثل و غيره من إصدار (Vista, ... تشغيل النوافذ على أن تكون هذه الأجهزة متصلة بشبكة الإنترنت عن طريق أي نوع من الاتصالات ـسواء من خلال الاتصـال بأي رقم أرضي أم من خلال خدمة (ADSL) - ومحمل عليها برامج البحث في لي الانترنت وبرامج متصفح الإنترنت مثل إنترنت إكسبلورر (Internet Explorer) أو فايرفوكس (Firefox) أو جوجل كروم (Chrome) مناحة مجانًا عبر (Web Browsers) الثبكة تساعد على تصفح الدليل، كما يمكن طباعة المعلومات المسترجعة من خلال 
ومتخذي القرار وكذلك المستثمرين في

قطـاع البترول في مسر مـن خـلال

البيانات و المعلومات التي يقدمها الدليل ومثال ذلك التعرف على عدد شركات البترول في مصر، و أنواعها المختلفة ونوزيعها العددي و النسبي، و أكثر و أقل

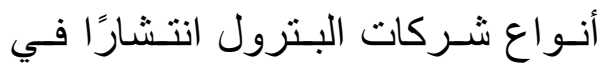

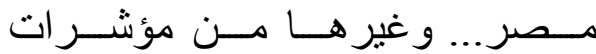
إحصائية تصف و اقع شركات البترول في مصر و التغيرات التي تطر أ عليها بمـا يسـاعد صـانعي القرار في بنـاء الخطط وصياغة المقترحسات لتطوير هـذا القطـاع بالاعتمـاد على بيانـات ومعلومات حقيقية. ؛ـ عالمية الإفادة ؛ إذ إن الإفادة من الاليل

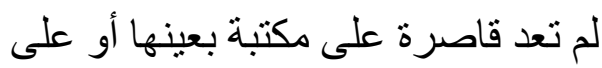
زمان دون آخر كما هو الحال في المصادر المرجعية المطبوعة بل ساعد إناحة هذا المصدر إلكترونيًا في إفادة كل من مستخدمي الإنترنت ومرتاديه و الباحثين و الدارسين وصانعي القرار و المستثرين و واختصاصيي المراجع وجميع المكتبات ومرافق المعلومات ولمين المتخصصة أو المهتمة بمجال البترول في مصر متجاوزين قيود الزمان ومحددات المكان المفروضة على كافة
أهمية "دليل شركات البترول" بوصفه أحد مصادر المعلومات المرجعية الإكترونية المئية التي جاءت لتسد فجوة؛ إذ إنه يُمَكِن اختصاصيي المراجع من تقديم إجابات لكل باحث ودارس وصانع قرار ومستثمر ومهتم وعامل في مجال البترول عن شركات البترول في مصر، وأنه إضافة جيدة إلى فئى

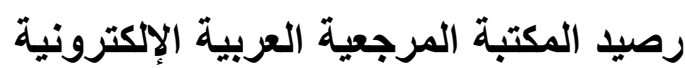
في ظل ما يتسم به من مميزات تتمثل في :

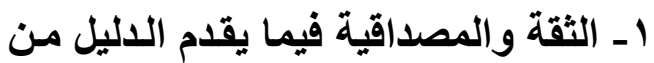
بيانات ومعلومات عن شركات البترول في مسر في ظل إعـداده و إتاحتهـ إلكترونيًا من جانب "وزارة البترول

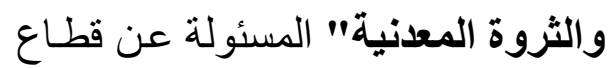
البترول والثروة المعدنية في مصر. r- سـهولة وبساطة وسـرعة البحث في اللاليل ودقة نتائجه، ووضوح ونقاء المعلومـات المعروضـة على الثشاثـة، بالإضـافة إلـي تعـد المــاخل القابلــة للبحث و الاسترجاع ومن ثم تعدد بدائل البحث وتتو عها أمسام المستفيد ليختار منها ما يلبي حاجاته فضلا عن إمكانية الربط بين أكثر من مدخل استرجاعي.

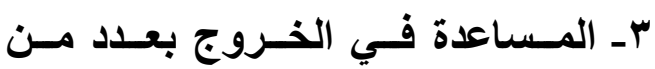

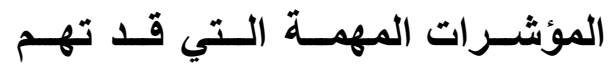
العــاملين والبــاحثين والدارســين 
على الاليل وتقييمه وتقييم مدى شـوله و اكتمـال بياناته، ومن ثم تحديد مدى تلبيـة الدليل لاحتياجاتـه، كمـا لا يوفر الدليل أيضًا نشرة إخباريـة أو موجز إرشادي مطبوع أو أي إشارة لتوضيح تـاريخ إنشاء الـليل، وتـاريخ إتاحتهـ إلكترونيًا وأهم التطورات التي تطر أ عليه وآخر التحديثات. r - عدم توفير الدليل لبعض الأيقونات المهر توفير ها بما يعاون المستخدم في سـهولة اسـتخدامه بـدلا مـن البحث عن طـرق

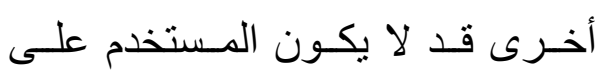
معرفـة أو خبرة تقنيـة بهـا؛ فـلا يوفـر الـدليل أيقونـة تـسـاعد المستخدم في في طباعـة نتـائج البحـث في الـدليل، ولا يوفـر أيـضًا أيقونــة تـسمح بالاختيـار بمـا بـسـاعد المـستخدم (Select All) الر اغب في طباعـة كل نتيجـة البحـث دون الحاجة لاستـعر اض كل صفحات نتيجة البحث وطباعتها صفحة صفحة علـى ســبيل المثثـال كــل البيانــات و المعلومـات الـتي يقدمها الـدليل عـن شـركات البترول الأجنبيـة في مـر ، وكذا لا يوفر أيقونـة تسمح بالاختيـار بجانـب اسـم كل شـركة مـن (Select)

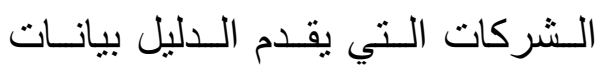

المستفيدين من المصادر المرجعية التقليدية المطبو عة.

•ـ تعدد اللغات التي يتّاح بها الاليل؛ إذ إنها

على النحو السابق تناولـه يتـاح باللغـة العربيـة على الواجهـة باللغــة العربيـة لموقــع "وزارة البــترول والــثروة

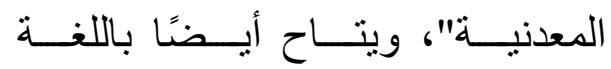
الإنجليزيـة عبر واجهـة الموقع باللغـة

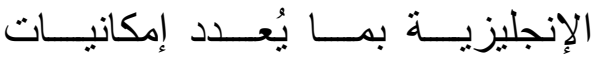
استعر اضهه أمام المستفيد بأكثر من لغة، ويساعد في الإطلاع عليـه من جانب المستفيد غير العربي مستخدم واجهة الموقع باللغة الإنجليزية. ولا يبقى إلا أن يراعي القائمين على الاليل بعض الملاحظات التي كثف تقييمه عنها والمتمثلة في : ا - عـدم وجـود مُقدمــة علـى الـصفحة الرئيسية للاليل تُعرف به وما يقدم من ون معلومـات، و على مَنْن تقع مسئولية

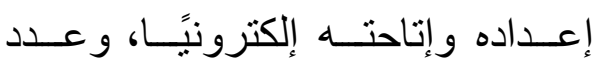
وحدات المعلومـات التي يقدم الدليـل معلومات عنها، ونطاق التغطيـة الكميـة و المكانية و الموضو عية، و الأشكال التي يظهر فيها الدليل ممـا بسـاعد الباحث و الــدارس واختصـاصـيـي المراجـع والمهتم المستفيدون منـه في التعـرف 
باللغة الإنجليزية معلومات عن ( VA ) شركة من شركات البترول سواء كانت قطـاع عـام أم اسـتثماري أم أجنبي أم مشترك في مصر بنقص مقداره ست وحدات (شـركات) معلومـات عن تلك التي يقدم الـلـليل معلومـات عنهـا مـن خلال واجهة الموقع باللغـة العربيـة؛ إذ إنها يقدم مـن خـلال الواجهة الإنجليزيـة معلومات عن :

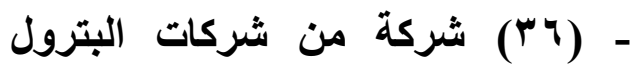
المشتركة.

- (Y Y ) شركة من شركات بترول القطاع

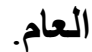

- (^^) شركة من شركات البترول الاستثمارية.

- - (צY) شركة من شركات البترول الأجنبية.

بما يوضح عدم اهتمام القائمين على الدليل بالتحديث الدوري للنسخة الإنجليزية للاليل على النحو الذي تُحدث بـه النسخة العربية المتاحة على واجهة الموقع باللغة العربية ويفضي إلى التوجيه بضرورة الاهتمام بتحديث نسخة الدليل الإنجليزية المتاحة على واجهة الموقع باللغة الإنجليزية وأن يكون هنالك تطابق بين النسختين.
ومعلومـات عنهـا بمـا بسـاعد المستخدم الر اغب في طباعـة جـزء مـن نتيجـة البحث باختيـار الشركات التي يرغب في طباعـة البيانـات و المعلومـات التي يقدمها الدليل عنها دون إلز امسه بطباعـة بيانـات ومعلو مـات عن شـركات قد لا يكون في حاجـة لبيانـات و المعلومـات عنها، أو أيقونة تساعد في عرض نتيجة البحثث في شكل قائمـة كاملـة بمـا بُعدد إمكانية الاختيار أمـام المستخدم مـا بين اسـتـعر اض نتيجـة البحــث في شـكل صفحات والتنقل بينها أو عرضـها في شكل قائمة تعرض كل نتيجة البحث في صفحة و احدة. rـ تبـاين المعلومـات التي يقدمها الدليـل باللغة العربية عبر واجهة الموقع باللغة العربية واختلافها عن تلك التي يقدمها مـن خـلال واجهـة الموقـع باللغــة الإنجليزية ؛ فقد كشفت المضاهاة بين المعلومـات الـتي يقدمها الـدليل عبـر واجهـــة الموقــع باللغــــة العربيــــة و المعلومـات التي يقدمها الـدليل عبـر واجهـة الموقع باللغــة الإنجليزيـة عـن إهــال القـائمون على الـدليل لنسخة الدليل الإنجليزيـة المتاحة على واجهة الموقع باللغة الإنجليزيـة ؛ فيقدم الدليل 
وكـللك المكتبـات العامـة ليجــ فيـه كـل اختصاصسي مراجع وباحث ودارس ومهتم وعامل وصانع قرار ومستثمر ومثقف عام مـن ذوي الاهتمـام معلومسات عن شـركات البترول في مصر.
ع - حاجة بعض المصطلحات المستخدمة في

ترجمـة الدليل بالإنجليزيـة على واجهة الموقـع باللغــة الإنجليزيـة إلـى تنقيـح ور اجعـة وتعـديل؛ على سبيل المثـال يـترجم عنـوان الـدليل إلـى الإنجليزيـة (Petroleum Companies Site) في حيـن أن الـصحيح ( Petroleum Oil (companies directory (companies directory نــوع الـشركات الأجنبيـة علـى الدليـل بالإنجليزيــة إلـى ( Multinational Foreign (companies .(companies

وفي ظل أهميـة الدليل وعلى ضوى

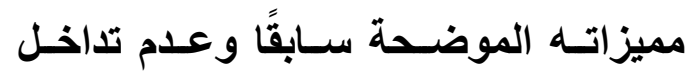
معلوماتهـه أو تكرارهـا مـع مصادر مرجعيـة إلكترونيـة أخرى وتعدد الفئـات التي يمكن أن تسترشد به فإنه من الثُهم إضافة "دليل شركات البـرول" إضـافة جيدة إلي قائمسة المـصادر المرجعيــة العربيـة الإكترونيـة ويمكن اقتنائهـ داخل مكتبـة وزارة البترول والــثروة المعدنيـة، ومكتبــات شــركات البتزرول، كمـا يمكن استخدامه في جميع المكتبات ومر افق المعلومات المتخصصة أو

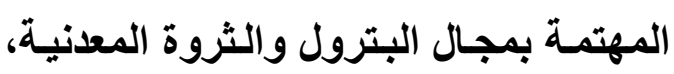

